\title{
Methicillin-Resistant Staphylococcus aureus and the Eye: Current Concepts and Management Strategies
}

\author{
David Ritterband
}

Published online: 30 October 2013

(C) Springer Science + Business Media New York 2013

\begin{abstract}
Methicillin-resistant Staphylococcus aureus (MRSA) remains one of the most important causes of nosocomial infections worldwide. This review explores the history and epidemiology of MRSA infections with a detailed analysis of its molecular subtyping, target populations, virulence factors, and modes of transmission. In addition, it specifically discusses the spectrum of eye diseases caused by MRSA, reviews the current ophthalmic literature, addresses the controversy regarding ophthalmic antibiotic resistance to MRSA, and examines alternative treatment strategies.
\end{abstract}

Keywords Methicillin-resistant Staphylococcus aureus . MRSA · Infection · Eye

\section{Introduction}

Staphylococcus aureus is among the most important and commonly isolated human bacterial pathogens. Infections caused by Staphylococcus aureus range from minor skin and soft tissue infections to life-threatening systemic infections. Staphylococcus aureus is also a leading cause of ocular infections include conjunctivitis, keratitism and endophthalmitis $[1,2 \bullet, 3,4 \bullet, 5]$.

Traditionally, methicillin-resistant Staphylococcus (MRSA) was almost exclusively associated with hospitals or hospital associated healthcare facilities, but its prevalence has increased in otherwise healthy patients without identifiable risk factors,

D. Ritterband ( $\square)$

Department of Ophthalmology, The New York Eye \& Ear Infirmary, 310 East 14th Street, New York, NY 10003, USA

e-mail: ritterband@msn.com such as admission to a hospital, intravenous drug use, or prior antibiotic exposure [6,7]. Such infections termed "community-associated" (CA) MRSA were clinically, microbiologically, and genetically different from healthcare-associated (HA) strains of MRSA. However, the distinction between the strains is blurring, as CA strains have migrated into the institutional setting $[8,9,10 \bullet, 11 \bullet \cdot]$.

\section{Staphyloccocal aureus}

Staphyloccocal aureus is a facultative anaerobic Grampositive coccal bacterium. Staphylococci are widespread in nature with their major habitat being skin and mucus membranes. The genome of $S$. aureus consists of a circular chromosome of approximately $2.8 \mathrm{Mb}$ predicted to carry $\sim 2,500$ genes $[12,13]$. Genes governing virulence and antibiotic resistance reside on both the chromosome and extrachromosomal elements [14]. These genes may be transferred between other $S$. aureus strains or other bacterial species via extrachromosomal elements [15].

\section{MRSA History}

Following the introduction of penicillin in the 1940s, the first antimicrobial drug to show effectiveness against staphylococcal infections, S. aureus developed penicillin resistance within a few months [16]. The molecular determinant responsible for penicillin resistance was identified as a plasmid-encoded $\beta$-lactamase gene capable of cleaving the $\beta$-lactam ring of penicillin $[17,18]$. Methicillin, a semisynthetic derivative of penicillin that is resistant to cleavage by $\beta$-lactamase, was introduced for clinical use in 1959 . Soon after, infections by $\beta$-lactamase 
producing penicillin-resistant strains sharply declined [19]. However, within 2 years following the introduction of methicillin, resistant strains were isolated in hospitals in the United Kingdom and subsequently in the United States [19]. Soon after, MRSA became endemic worldwide [13].

The term MRSA is used loosely, since methicillin, in the strict sense, is not an antibiotic in current clinical use. A more contemporary definition incorporates both minimum inhibitory concentration (MIC) and molecular criteria. Intrinsic resistance to methicillin and similar antibiotics through the acquisition of modified penicillin binding proteins is a major distinction for the MRSA phenotype $[20 \cdot 21]$.

\section{Epidemiology of MRSA}

Methicillin resistance in staphylococci is associated with the acquisition of a mobile genetic element (MGE) called the staphylococcal cassette chromosome mec (SCCmec) $[11 \bullet \cdot, 22,23]$. SCCmec is a DNA fragment ranging from 21 to $67 \mathrm{~kb}$ in size depending on the SCCmec type [24].

For most of the past 50 years, MRSA was considered to be mostly a nosocomial pathogen with a limited number of clonal backgrounds causing serious infections in individuals with HA risk factors. HA-MRSA are among the most common causes of nosocomial infections including intravenous catheter associated infections, ventilator associated pneumonias, and surgical wound infections. In addition MRSA are the most common cause of skin and soft tissue infections in the United States [25, 26].

In the 1990s, reports of de novo CA-MRSA infections among healthy individuals began to appear in the literature and were found to have genetically distinct lineages unrelated to existing HA-MRSA strains [11••, 27]. The first case of CA-MRSA was reported in 1993 in a remote part of Western Australia lacking any close healthcare facility [28]. Shortly thereafter, CA-MRSA appeared in the USA, causing the deaths of four children from rural Minnesota and North Dakota (CDC [29]). Since that time, numerous lineages of CA-MRSA emerged across the globe $[9,10 \bullet$, $1,11 \bullet \cdot$. The history of the onset of CA-MRSA in the US has been reviewed elsewhere in great detail and is beyond the scope of this article [26, 30-32].

These highly successful CA-MRSA clones have invaded the healthcare setting and are increasingly being implicated in nosocomial infections. Mathematical models appear to predict that they will ultimately displace traditional HAMRSA strains in the healthcare setting [23, 30]. A high number of CA-MRSA infections are being observed in the USA, but also in increasing frequency in other parts of the world, reaching pandemic proportions [23, 30, 33]. The fact that the CA-MRSA epidemic is particularly severe in the USA is likely due to single epidemic clone USA300. The USA-300 isolate appears to have enhanced virulence as well as an enhanced capacity to colonize multiple body sites and to survive on environmental surfaces $[23,28,30$, 34, 35].

The absolute definitions of CA-MRSA and HA-MRSA are the subject of controversy. According to the current definition, CA-MRSA infections are those for which the onset of infection is within $48 \mathrm{~h}$ of admission to the hospital with no previous history of hospitalization in the past year, whereas HA-MRSA is defined by the onset of infection occurring after $48 \mathrm{~h}$ of hospital admission [33]. The most contemporary definitions now incorporate both MIC and molecular criteria. Consequently, traditional distinctions between HA-MRSA and CA-MRSA based on clinical epidemiology and susceptibility are becoming less apparent [9]. Currently, an increasing number of reports from the USA and abroad indicate that CA-MRSA isolates are gradually replacing HA-MRSA in hospitals [20•, 35].

\section{Molecular Typing of MRSA}

A unique feature of the worldwide pandemic of MRSA infections has been the discrete number of staphylococcal clones associated with these events [27]. Unlike the diversity of strains seen with methicillin-sensitive $S$. aureus, the MRSA outbreaks have been limited to a relatively small number of lineages. Overtime, these lineages have evolved, accumulating mutations that alter their gene expression and function. In addition, new genetic elements obtained via horizontal gene exchange have allowed the MRSA to alter animal species specificity, the nature of their invasive infections, and, most importantly, the type of antimicrobial resistance associated with the strains [36].

The precise molecular typing methods employed to categorize $S$. aureus and the clonal subtypes are beyond the scope of this review. The four primary methods used internationally are pulsed-field gel electrophoresis (PFGE), multilocus sequence typing, spa typing, and SCCmec typing for MRSA [28, 37-39]. PFGE is a genotyping or genetic fingerprinting method commonly considered a gold standard in epidemiological studies of pathogenic organisms. It indexes variation that accumulates rapidly, and is particularly appropriate for studies of outbreaks or shortterm epidemiologic studies [37]. The PFGE database in the USA classifies major $S$. aureus clones as USA100, USA200, USA300, and so on. Well-known international designations include EMRSA (United Kingdom), WAMRSA (Western Australia), and CMRSA (Canada) [11••]. Although current typing methods are highly useful for tracking S. aureus outbreaks, and provide important information for our understanding of pathogen evolution, 
they index variation at a relatively small number of nucleotides. Whole-genome sequencing approaches have the ability to provide the full extent of genetic diversity among isolates, and this method will become increasingly employed in the future [26].

\section{Target Populations and Transmission}

Staphylococcus aureus is a frequent asymptomatic colonizer of humans. Roughly a third of the human population carries $S$. aureus primarily in the nares, nasopharynx, groin, and perineum $[40,41]$. The occurrence of nasal MRSA colonization in the human population is estimated to be about $1.5 \%$, of which roughly one in six carries a CAMRSA strain $[42,43]$. There are several risk factors for the acquisition of a MRSA infection. Most commonly, an individual is at a high risk for infection from his or her own colonizing strain [44]. Poor personal hygiene and a compromised skin barrier are believed to play important roles in CA infections, while underlying conditions such as a compromised immune system increase the risk for MRSA infection in hospital infections.

MRSA is prevalent in healthcare workers, and cumulative evidence suggests they may serve as a reservoir for the spread of HA-MRSA infections in hospitals [20•, 28, 45]. MRSA has been increasingly associated with livestockassociated (LA-MRSA) infections over the last four decades [46-49]. Recent reports have shown LA-MRSA strains infecting livestock-associated workers [50] and the transmission of USA100, -300 , and -500 strains between humans and their companion animals [46, 50-53]. The recent breach of the genus barrier by strains of LA-MRSA indicates that livestock may serve as an additional reservoir for human infections $\left[20^{\bullet}, 46\right]$.

The target population for MRSA infections is diverse. Groups at high risk for CA-MRSA include prison inmates [54], military personal [54], athletes [55], and IV drug users [54]. In addition, the elderly, children [56], patients with indwelling medical devices [57], and people with underlying disease conditions, including diabetes [58], neutrophil dysfunction [59], and HIV/AIDS patients [60], are also at increased risk.

The target population of MRSA infections in the eyes is varied and generally mimics that seen in systemic infections. Reports of MRSA ophthalmic infections are numerous in the literature. They are more commonly seen in patients in neonatal ICUs [61-63], in post-ocular surgical patients [64-75], among healthcare workers[76, 77] after corneal refractive surgery [77-84], in hospitalized pediatric patients [85], and in patients with chronic medical disease, immuno-suppression, or immunodeficiency $[70,86]$.

\section{Virulence Factors}

The success of $S$. aureus as a pathogen is due to a large extent to its ability to resist antimicrobial agents and circumvent the immune surveillance of the host. MGEs play an essential role in this process and are a means to transfer genetic information within species. Many molecular determinants of resistance and virulence are encoded on MGEs. S. aureus possesses an enormous repertoire of virulence and persistence genes [20 ${ }^{\bullet}$. Some of the more commonly studied virulence factors include genomeencoded pore-forming $\alpha$-toxin [87], PSMs, which are a small group of genome-encoded cytolytic peptides that are key determinants in the development of skin, bloodstream, and biofilm-associated infections [23, 88], and leukotoxins, such as Panton-Valentine Leukocidin (PVL), the effect of which on the pathogenesis of MRSA infection is complicated by its epidemic association with CA-MRSA infections, even though animal and human studies have failed to find PVL as a factor in $S$. aureus virulence The reader is referred to review articles presenting the molecular basis of $S$. aureus virulence in more detail [23, 89].

\section{Spectrum of Eye Disease}

Staphylococcus aureus bacteria are of great interest in ophthalmology, due to their role as a leading pathogen in infections such as conjunctivitis, keratitis, and lid and lacrimal infections. Until recently, studies of ocular MRSA infections have generally been limited to case reports and small case series from single institutions [1, 61-86, 91]. The scant information on ocular infections and the variety of definitions for CA-MRSA [9, 33, 92, 94] makes comparing and contrasting published studies difficult. In addition, many of the earlier studies on MRSA ophthalmic infections do not distinguish CA-MRSA from HA-MRSA entities. Few if any base the distinctions on epidemiologic differences and genomic typing.

Rutar et al. reported on the ophthalmic manifestations of CA-MRSA infections with USA 300 clone in 9 isolates, including orbital cellulitis, endogenous endophthamiitis, and panophthalmiits, and lid abscesses. This was the first report to raise the alarm of aggressive MRSA infections in hospital-naïve patients [91].

Few studies reviewing the epidemiologic, demographic, and microbiologic features of ocular MRSA infections, both HA- and CA-based, in a defined population over a minimum of 5 years exist $[2 \bullet, 4 \bullet, 94]$. This may be a result of the fact that most ophthalmic patients are treated in an outpatient setting and treated empirically without culturing based on clinical examination. 
Most recently, Amato et al. reported on a retrospective cross-sectional review of all pediatric cases (aged 0-18 years) with culture-positive ophthalmic MRSA in a northern California pediatric population from 2002 to 2009. A total of 137 ocular and periocular pediatric MRSA cases were reviewed. Of the 137 cases, $58 \%$ were community acquired. Conjunctivitis was the predominant presentation $(40 \%)$, followed by stye/chalazion $(25 \%)$, orbital cellulitis/abscess (19\%), dacryocystitis (11\%), and brow abscess (3\%). The authors reported that pediatric ocular and periocular MRSA was increasing in incidence and resistance in this population [93].

In 2012, Hsiao et al. identified 274 patients with MRSA ocular infections in a 10-year hospital-based study in Taiwan. This included $181 \mathrm{CA}-\mathrm{MRSA}$ infections and $93 \mathrm{HA}-$ MRSA infections. They defined CA-MRSA and HAMRSA infections according to the definition proposed by Naimi et al. and advocated by the CDC [4•,94]. During the study, S. aureus was isolated from 519 patients, and 274 $(52.85 \%)$ of them were MRSA (181 CA-MRSA and 93 HA-MRSA). The infections included 99 cases of keratitis, 67 cases of lid infections (cellulitis, lid abscess, hordeolum), 28 cases of lacrimal system involvement (canicullitis, dacryocystitis), 10 cases of wound infection, 9 cases of endophthalmitis, and 5 cases of other infections (blebitis, sclera ulcer, scleral buckle infection, and hydroxyappetitie implant infection). They found HA-MRSA most commonly caused keratitis (47 of 93 cases), but the rate significantly decreased to 63.5-34.1\% during the last 5 years of the study, while the rate of lid disorders caused by CAMRSA increased from 17.2 to $37.6 \%$ over the 10 -year period. In summary, they reported that approximately twothirds of ocular MRSA infections were CA and the proportion increased over time. Patients with ocular CAMRSA infections were younger and had milder disease; they tended to have lid and lacrimal disorders [4•].

Blomquist, in 2006, reported an increased prevalence of ocular MRSA infections in an urban public healthcare system from 2000 to 2004 [2•]. In this 5-year period, 3,540 patients were identified with culture-positive MRSA infections, with 1,088 (30\%) considered to have acquired the isolate via nosocomial transmission and 2,552 (70\%) considered to have CA-MRSA. Not surprisingly, since the most common manifestations of CA-MRSA are skin and soft tissue infections, his data showed a prevalence of MRSA involving the lids. Forty-nine patients $(1.2 \%)$ had ophthalmic MRSA involvement. Twenty-two patients (42\%) had either pre-septal cellulitis, a lid abscess or both, eleven patients had conjunctivitis ( $21 \%$; 6 CA-MRSA), five patients $(10 \%, 2$ CA-MRSA) had keratitis, four patients endogenous endophthalmitis (8\%; 4 CA-MRSA), and there were two patients each with blebitis (1CAMRSA), dacryocystitis (1-CA-MRSA), and orbital cellulitis with endophthalitis (4\%). One patient had an orbital abscess (2\%) [2•].

Many of the additional reports are laboratory based from records collected from microbiology databases and do not have detailed records of the clinical history or the epidemiologic data. Freidlin et al. reported on 915 positive S. aureus cultures over an 18-year period (1998-2006), they found 88 MRSA isolates. The percentage of MRSA isolates increased from $4.1 \%$ in $1998-1999$, to $16.7 \%$ in 2005-2006. They had $78 \%$ with blepharoconjunctivitis, $2.4 \%$ with cellulitis, $2.4 \%$ with dacryocystitis, $14.6 \%$ with keratitis, and $2.4 \%$ with endophthalmitis [1]. Lichtinger [95] in an 11 year review of bacterial keratitis in Toronto, found MRSA represented only $1.3 \%$ of the 977 positive corneal scrapings taken over an 11 year period at one institution.

In the last decade, two institutions with dedicated ocular microbiology laboratories have presented their data. Miller et al. examined $484 \mathrm{~S}$. aureus isolates recovered during a 6-year period from 2000 to 2005 at the Bascom Palmer Eye Institute (BPEI). Their overall MRSA recovery rate was $29.1 \%$ (141/ 484). Ocular source rates in descending order were: orbit $33.0 \%$, conjunctiva $29.3 \%$, and lids $28.8 \%$. Of the ocular MRSA isolates, $37 \%(53 / 141)$ were resistant to 2 or fewer antibiotics. Resistance to the macrolides, clindamycin, and the fluoroquinolones was most commonly seen [3].

Shah et al., from the New York Eye and Ear Infirmary, reported on $16,815 \mathrm{~S}$. aureus isolates recovered over a 26-year period [127]. They tabulated their data per decade. From 1984 to 1989, 2,231 isolates were cultured and 155 (6.9\%) were MRSA. From 1990 to 1999, 6,737 S. aureus were cultured of which $685(10.1 \%)$ were MRSA. And, from 2000 to $2009,7,434 S$. aureus isolates were cultured of which 966 (13.4\%) were MRSA. In 2010, 415 S. aureus isolates were cultured of which $83(20 \%)$ were MRSA. They noted an increase prevalence of MRSA isolates each decade but no increase in the prevalence of $S$. aureus ulcers over the time period.

In addition to the series above, a comprehensive review of all published MRSA related ocular infection case reports and retrospective small case series is not possible, but Table 1 summarizes the most current MRSA-related case reports and small series in the literature based on infection site and/or specific populations [23, 62-108]. Perhaps the most common are those reported after eye surgery and/or concerning post-operative endophthalmitis. Recent reports in the last decade on endophthalmitis or postoperative infection include small retrospective cases series or case reports following cataract surgery [65, 70, 83, 98], after amniotic membrane transplantation [64], following scleral buckle placement [68], following PK [69], following Ahmed valve placement [71], and after cornea refractive surgery [77-84]. Other reports are frequently site-specific, 
including orbital cellulitis [99-104], lacrimal system involvement [91, 105-107], and, most recently, after brow epilation [108].

\section{Ophthalmic Resistance of MRSA}

Historically, isolates obtained sporadically and especially from community sources were more likely to be antibiotic susceptible [45]. Continued and occasional inappropriate use of systemic antibiotics has given rise to selective pressure favoring multi-drug-resistant bacterial strains. Such resistance for non- $\beta$-lactam antibiotic variably includes aminogylcosides, macrolides, clindamycin, tetracylcine, fluoroquinolones, and sulfas among others. MRSA resistance continues to evolve, with expanding resistance to a broad variety of antimicrobial agents. In the hospital setting, it is now becoming a multi-drug-resistant pathogen and showing increasing resistance in CA infections [5, 109, 110•].

Resistance among ocular pathogens is increasing in parallel with the increase among systemic pathogens [110, $111 \bullet \cdot, 112]$. Data on MRSA antibiotic sensitivity solely from ophthalmic sources has generally been limited to reports from single institutions and retrospective case series $[3,81,83,110 \bullet, 111 \bullet, 112]$. However, recent antibiograms from the US and abroad showed that CA-MRSA strains tended to be susceptible to a wide range of non- $\beta$ lactam antibiotics $[3,4 \bullet, 93,113]$.

In the Blomquist report, all ocular CA-MRSA and HAMRSA isolates were sensitive to trimethoprim/sulfamethoxazole and vancomycin, and more than $80 \%$ of both strains were sensitive to tetracycline and gentamicin [2•]. In the Amato series of pediatric patients, high sensitivities to oral trimethoprim-sulfamethoxazole, gentamicin, and vancomycin were found [93]. This was also seen in the data from Miller et al. [3] at the Bascom Palmer Eye Institute and by Shah et al. [127] at the New York Eye and Ear Infirmary.

Increasing prevalence of MRSA ophthalmic infections has been much ballyhooed in both the peer-reviewed ophthalmology as well as the non-peer-reviewed ophthalmology "throwaways". Asbell et al. [110•] reported increasing prevalence of multi-drug-resistant MRSA in serious ocular infections based on the rate of increase in a national surveillance program monitoring evolving patterns of antimicrobial susceptibility for pathogens requiring diagnostic testing. The Surveilllance Network (TSN) retrieved data from over 580,000 isolates of S. aureus from 2000 to 2005 and found methicillin resistance increased in $S$. aureus isolates regardless of specimen source. The MRSA prevalence rate increased $12.1 \%$ during the 5-year period (from $29.5 \%$ in 2000 to $41.6 \%$ in 2005) [114].
Table 1 Methicillin resistant S. aureus ophthalmic cases in literature

Larger case series (clinical descriptions/treatment)

Blomquist et al. [2•]

Hsiao et al. [4•]

Amato et al. [93]

Small case series (based on microbiology results or drug trials)

Shanmuganathan et al. [123]

Rutar et al. [91]

Adebayo et al. [124]

Lichtinger et al. [95]

Sotonzono et al. [118]

Case reports site-specific

Lacrimal system

Kotlus et al. [90]

Rutar [107]

Kubal and Garibaldi [105]

Chandravanshi et al. [106]

Gould et al. [125]

Conjunctiva

Tarabishy et al. [85]

Cimolai [61]

Ikeda et al. [119]

Mantadakis et al. [113]

Cellulitis

Mehra et al. [98]

Charalampidou et al. [99]

Juthani et al. [101]

Vaska et al. [104]

Soon [100]

Mathias et al. [102]

Endophthalmitis

Deramo et al. [96]

Major et al. [97]

Ursea et al. [126]

Ho et al. [86]

Basu et al. [62]

Keratitis

Sotozono et al. [67]

Lee et al. [69]

Chou et al. [65]

Post-surgical case reports

Cataract surgery

Cosar et al. [75]

Tang et al. [70]

Retinal surgery

Oshima et al. [68]

Feiz and Redline [72]

Rich et al. [74]

Pterygium surgery

Lee et al. [73] 
Table 1 continued

Glaucoma surgery
Park and Rabowsky [71]
Ocular surface reconstruction
Hori et al. [64]
Cornea cross-linking
Bödemann and Kohnen [66]
Post refractive surgery
Solomon et al. [77]
Woodward and Randelman [78]
Nomi et al. [80]
Magli et a.1 [79]
Karth and Karth [83]

Published reports of MRSA infections specifically after refractive surgery and cataract surgery at that time raised an ominous specter concerning these infections, especially in light of the fact that many of the cultured organisms had been fluoroquinolone-resistant [75, 77-84]. However, many of the published small reports lack the study power to definitively illustrate the epidemiology of these infections. In addition, ophthalmic culturing practices and geographic location can skew the data and over-represent post-operative infections, infections that respond poorly to initial therapy, and present as severe and potentially sight-threatening infections.

Confounding these MRSA resistance reports is the fact that standard breakpoints for topical antibiotic therapy are not available, and susceptibility data on ocular pathogens is based on the Clinical and Laboratory Standards Institute (CLSI) criteria. These susceptibility/resistance breakpoints are based on drug levels expected in the serum or cerebral spinal fluid after oral or intravenous administration. Although in vitro data are generally accepted as predictive of clinical response, they do not ensure it. Nonetheless, given the high concentration of antibiotics that can be applied directly to the eye, it is generally accepted that antibiotic levels given topically can likely reach or be higher than the CLSI-defined breakpoints for $S$. aureus resistance $\left[110 \bullet, 111^{\bullet}\right]$. Hoishi et al. [115], in an in vitro model, were able to demonstrate post-antibiotic effects and increased bactericidal activity against MRSA strains with high- and low-level resistance to levofloxacin and/or gatifloxacin when both antibiotics were given at concentrations simulating topical administration.

\section{Treatment}

The majority of antibiotics used to treat MRSA infections target bacterial cell wall synthesis or protein synthesis. Only daptomycin has a novel mode of action [116]. Among the agents currently recommended by the Infectious Disease
Society of America are vancomycin, clindamycin, daptomycin, linezolid, trimethoprim, tetracycline, and the strepogramins (quinupristin/dalfupristin) [117].

A quick perusal of the above medications shows only trimethoprim as an agent available commercially for topical application in the United States. So why are we not seeing a pandemic of ophthalmology infections with MRSA? In my opinion, there may be several answers. First, the MRSAassociated conjunctivitis cases may be self-limiting or controlled with high-dose fluoroquinolone antibiotics topically applied in the United States as first-line therapy. Rarely if ever have I needed to resort to fortified vancomycin to treat chronic MRSA conjunctivitis poorly responsive to therapy. Secondly, many of these infections have been reported in susceptible populations such as hospitalized children or in neonatal units, and these patients may also have concomitant systemic colonization and therefore are treated with appropriate systemic therapy $[2 \bullet, 21,85,117]$. Recently, several Japanese authors have reported clinical success in external ocular infections and/or conjunctivitis with minocycline ointment and vancomycin $1 \%$ ointment $[118,119]$.

In terms of the most severe ocular infections (bacterial keratitis and endophthalmitis), these are commonly treated with intravitreal vancomycin endophthalmitis and fortified topical vancomycin for keratitis. Most of the aforementioned ocular infections in the small case series were treated successfully with traditional endophthalmitis or keratitis protocols, and few if any of the small case reports made alternative treatment suggestions. Our standard regimen for moderate to severe keratitis at the NYEEI is fortified vancomycin and either a later generation fluoroquinolone or an aminoglycoside. Our standard intravitreal protocol also uses vancomycin for Gram-positive organisms and ceftazidime for Gramnegative infections. The lacrimal system infections and orbital infections are treated systemically, and the antibiotic choices can be modified upon culture results.

However, the question is still left unanswered, is our current success short-lived? There are certain strategies that may be useful to decelerate the progress of resistance. These include using culture-directed therapy when possible. If the MRSA is susceptible to an older agent like trimethoprim-polymyxin B, it can be employed. If possible, combination therapy and employing antiseptics like betadine can also play a role.

Although the anti-infective industry has focused on the development of newer generations of conventional antibiotics with improved therapeutic properties, several authors have recently highlighted areas where basic and applied research may offer novel anti-MRSA therapies. FitzgeraldHughes et al. [116] discussed cationic antimicrobial peptides and "antipathogenic agents" which interfere with bacterial virulence mechanisms (host binding, biofilm formation, evasion of phagocytosis, and toxin production) as novel therapies to combat MRSA. Cheung et al. [120•] discussed 
an immunization therapy that potentially uses multiple antibodies directed against a series of genome-encoded toxins of MRSA. Suzuki discussed antibiotics such as targocil targeting wall teichoic acids (WTA). WTAs are a major polyanionic polymer in the cell walls of S. aureus [121]. Koyama et al. [122] discussed several other avenues to target MRSA, including inhibitors of bacterial cell wall peptidoglycan, inhibitors of WTA, and inhibitors of virulence factors such as staphyloxanthin.

\section{Conclusion}

Staphylococcus aureus remains a remarkably successful pathogen. It has continued to thrive despite the availability of effective agents to treat it. It continues to be a major cause of morbidity and mortality worldwide. The success of $S$. aureus as a pathogen is due in large extent to its capacity to exist as a commensal, to resist antimicrobial agents, and to circumvent the immune surveillance of its host. MRSA are now well established in both the hospital and community settings. The emergence of CA-MRSA as an important ocular pathogen has occurred in the past 15 years. The ongoing emergence of resistant strains may be readily explained by selective pressure in the healthcare setting. The emergence of antibiotic resistance seen in the systemic literature has now been reported throughout the ophthalmic literature. There still remains a disparity between the prevalence of MRSA among cultured $S$. aureus isolates and the actual percentages of ocular infections caused by the organism. Although MRSA remains the most common cause of skin and soft tissue infections in the USA, the number and percentages of conjunctivitis, lid and lacrimal infections, keratitis, and endophthalmitis infections has not seen similar changes. We are left to wonder, is the epidemic wave of MRSA related ophthalmic infections coming or will the ophthalmic community need to employ new approaches to protect against the high disease burden offered by these organisms?

Disclosure David Ritterband declares that he has no conflict of interest.

Human and Animal Rights and Informed Consent This article does not contain any studies with human or animal subjects performed by any of the authors

\section{References}

Papers of particular interest, published recently, have been highlighted as:

- Of importance

-• Of major importance
1. Freidlin J, Acharya N, Lietman TM, Cevallos V, et al. Spectrum of eye disease caused by methicillin-resistant Staphylococcus aureus. Am J Ophthalmol. 2007;144:313-31.

2. B Blomquist P, et al. Methicillin-resistant Staphylococcus aureus infections of the eye and orbit. Trans Am Ophthalmol Soc. 2006;104:322-45. A single institution review of the prevalence of MRSA, both HA-MRSA and CA-MRSA ocular cases, over a 5-year period.

3. Miller D, Diaz MG, Perez EM, et al. Prevalence of community acquired methicillin resistant Staphylococcus aureus among ocular MRSA isolates. Am J Infect Control. 2006;34:E23-4.

4. - Hsiao CH, Chuang CC, Tan HY, et al. Methicillin-resistant Staphylococcus aureus ocular infection; a 10-year hospitalbased study. Ophthalmology. 2012;119(3):522-7. Another excellent single institution decade-long review of ocular MRSA infections and the first large series to compare HA-MRSA versus CA-MRSA among ocular infections.

5. Deresinski S. Methicillin-resistent Staphylococcus aureus: an evolutionary, epidemiologic and therapeutic odyssey. Clin Infect Dis. 2005;40:562-73.

6. Warshawsky B, Hussain Z, Gregson DB, et al. Hospital and community-based surveillance of methicillin-resistant Staphylococcus aureus: previous hospitalization is the major risk factor. Infect Control Hosp Epidemiol. 2000;221:724-7.

7. Herold BC, Immergluck LC, Maranan MC, et al. Communityacquired methicillin-resistant Staphylococcus aureus in children with no identified predisposing risk. JAMA. 1998;279:593-8.

8. Boyce JM. Community associated methicillin-resistant Staphylococcus aureus as a cause of health care-associated infection. Clin Infect Dis. 2008;46:795-8.

9. Chua K, Laurent F, Coombs G, Grayson ML, et al. Antimicrobial resistance; not community associated methicillin-resistant Staphylococcus aureus (CA-MRSA)! A clinicians guide to community MRSA-its evolving antimicrobial resistance and implication for therapy. Clin Infect Dis. 2011;52:99-114.

10. • David MZ, Daum RS. Community-associated methicillinresistant Staphylococcus aureus: epidemiology and clinical consequences of an emerging epidemic. Clin Microbiol Rev 2012; 23:616-87. An authoritative review of the entire spectrum of issues regarding CA-MRSA outside the narrow focus of ophthalmology.

11. •• Mediavilla J, Chen L, Mathema B, Kreiswirth B. Global epidemiology of community-associated methicillin resistant Staphylococcus aureus (CA-MRSA). Curr Opin Microbiol. 2012;15:588-595. An excellent review article for the nonmicrobiologist discussing molecular typing of $S$. aureus and the origins and emergence of CA-MRSA.

12. Bannerman T, Peacock S. Staphylococcus, micrococcus, and other catalase-positive cocci. In: Murray P, Baron E, Jorgensen, editors. Manual of clinical microbiology. Washington: ASM; 2007. p. 390411.

13. Lowy FD. Staphylococcus aureus infections. N Engl J Med. 1998;339:520-32.

14. Novick RP. The staphylococcus as a molecular genetic system. In: Novick RP, editor. Molecular biology of the staphylococci. New York: VCHL; 1990. p. 1-37.

15. Schaberg DR, Zervos MJ. Intergeneric and interspecies gene exchange in gram positive cocci. Antimicrob Agents Chemother. 1986;30:817-22.

16. Demerec M. Production of Staphylococcus strains resistant to various concentrations of penicillin. Proc Natl Acad Sci USA. 1945;31:16-24.

17. Murray BE, Moellering RC Jr. Patterns and mechanisms of antibiotic resistance. Med Clin North Am. 1978;62:899-923.

18. Abraham EP, Chain E. An enzyme from bacteria able to destroy penicillin. Rev Infect Dis. 1988;10:677-8. 
19. Jevons MP, Parker MT. The evolution of new hospital strains of Staphylococcal aureus. J Clin Pathol. 1964;17:243-50.

20. - Chatterjee S, Otto M. Improved understanding of factors driving methicillin-resistant Staphylococcus aureus epidemic waves. Clin Epidemiol. 2013;5:205-17. A nice review incorporating the history of MRSA, the emergence of CA-MRSA, and the target populations susceptible to transmission and the resultant pathology.

21. Cimolai N, Espersen F. Staphylococcal infections. In: Cimolai $\mathrm{N}$, editor. Laboratory diagnosis of bacterial infections. New York: Marcel Dekker; 2001. p. 229-55.

22. Katayama RM, Ito T, Hiramatsu K. A new class of genetic element, staphylococcus cassette chromosome mec, encodes methicillin resistance in Staphylococcus aureus. Antimicrob Agents Chemother. 2000;44:1549-55.

23. Otto M. MRSA virulence and spread. Cell Microbiol. 2012;14: 1513-21.

24. Hiramatsu K, Cui L, Kuroda M, Ito T. The emergence and evolution of methicillin-resistant Staphylococcus aureus. Trends Microbiol. 2001;9:486-93.

25. Rosenthal VD, Bijie H, Maki DG, INICC Members 2009, et al. International nosocomial infection control consortium (INICC) report, data summary of 36 countries for 2004-2009. Am J Infect Control. 2012;40:397-407.

26. Uhlemann A, Otto M, Lowy F, Deleo. Evolution of community and healthcare-associated methicillin-resistant Staphylococcus aureus. Infect Genet Evol. 2013;. doi:10.1016/j.meegid.2013.04.030.

27. Chambers HF, Deleo FR. Waves of resistance: Staphylococcus aureus in the antibiotic era. Nat Rev Microbiol. 2009;7:629-41.

28. Udo EE, Pearman JW, Grubb WB. Genetic analysis of community isolates of methicillin-resistant Staphylococcus aureus in Western Australia. J Hosp Infect. 1993;25:97-108.

29. CDC. From the centers for disease control and prevention four pediatric deaths from community-acquired methicillin-resistant Staphylococcus aureus-Minnestota and North Dakota, 1977-1999. JAMA. 1999;282:1123-5.

30. Deleo FR, Otto M, Kreiswirth B, Chambers HF. Communityassociated methicillin resistant Staphylococcus aureus. Lancet. 2010;375:1557-68.

31. Deleo FR, Chambers HF. Reemergence of antibiotic-resistant Staphylococcus aureus in the genomics era. J Clin Invest. 2009;119:2464-74.

32. D'Agata EM, Webb GF, Horn MA, Moellering RC, et al. Modeling the invasion of community acquired methicillin-resistant Staphylococcus aureus into hospitals. Clin Infect Dis. 2009;48:274-84.

33. Skov RL, Jensen KS. Community-associated methicillin-resistant Staphylococcus aureus as a cause of hospital infections. J Hosp Infect. 2009;54:3804-11.

34. Moran GJ, Krishnadasan A, Gowitz RJ, et al. Methicillinresistant $S$. aureus infections among patients in the emergency department. N Engl J Med. 2006;355:666-74.

35. Seybold U, Kourbatova EV, Johnson JG, et al. Emergence of community-associated methicillin-resistant Staphylococcal aureus USA300 genotype as a major cause of healthcare-associated blood stream infections. Clin Infect Dis. 2006;42:647-56.

36. Malachowa N, DLeo FR. Mobile genetic elements of Staphylococcal aureus. Cell Mol Life Sci. 2010;67:3057-71.

37. Enright MC, Day NP, Davies CE, et al. Multilocus sequence typing for the characterization of methicillin-resistant and methicillin-sensitive clones of Staphylococcus aureus. J Clin Microbiol. 2000;38:1008-15.

38. IWG-SCC. Classification of staphylococcal cassette chromosome mec (SCCmed): guidelines for reporting novel SCCmec elements. Antimicrob Agents Chemother. 2009;53:4961-7.

39. Stefani S, Chung DR, Lindsay JA, et al. Methicillin-resistant Staphyloccoccus aureus (MRSA): global epidemiology and harmonization of typing methods. Int $\mathrm{J}$ Antimicrob Agents. 2012;39:273-82.

40. Schechter-Perkins EM, Mitchell PM, Murray KA, et al. Prevalence and predictors of nasal and extranasal staphylococcal colonization in patients presenting to the emergency department. Ann Emerg Med. 2011;57:492-9.

41. Graham PL, Lin SX, Larson EL. A US population-based survey of Staphylococcus aureus colonization. Ann Intern Med. 2006; 114:318-25.

42. Gorwitz RJ, Kruszon-Moran D, McAllister S, et al. Changes in the prevalence of nasal colonization with Staphylococcus aureus in the United States, 2001-2004. J Infect Dis. 2008;197:1226-34.

43. Tenover FC, McAllister S, Fosheim G, et al. Characterization of Staphyloccoccus aureus isolates from nasal cultures collected from individuals in the United States in 2001-2004. J Clin Microbiol. 2008;46:2837-41.

44. Wenzel RP, Perl TM. The significance of nasal carriage of Staphylococcus aureus and the incidence of postoperative wound infection. J Hosp Infect. 1995;31:13-24.

45. Cimolai N. Methicillin-resistant Staphylococcus aureus in Canada: a historical perspective and lessons learned. Can J Microbiol. 2010;56:89-120.

46. Fitzgerald JR. Livestock associated Staphylococcus aureus: origin evolution and public health threat. Trends Microbiol. 2012;20:192-8.

47. Lowder BV, Guinane CM, Ben Zakour NL, et al. Recent humanto-poultry host jump, adaptation and pandemic spread of Staphylococcus aureus. Proc Natl Acad Sci USA. 2009;106: 19545-50.

48. Armand-Lefevre, Ruimy R, Andremont A. Clonal comparison of Staphylococcus aureus isolates from healthy pig farmers, human controls, and pigs. Emerg Infect Dis. 2005;11:711-4.

49. Cuny C, Friedrich A, Kozytska S, et al. Emergence of methicillin-resistant Staphylococcus aureus (MRSA) in different animal species. Int J Med Microbiol. 2010;300:109-17.

50. Fluit AC. Livestock-associated Staphylococcus aureus. Clin Microbiol Infect. 2012;18:735-44.

51. Walther B, Wieler LH, Vineze S, et al. MRSA variant in companion animals. Emerg Infect Dis. 2012;18:2017-20.

52. Morris DO, Lautenback E, Zaoutis T, et al. Potential for pet animals to harbor methicillin-resistant Staphylococcus aureus when residing with human MRSA patients. Zoonose Public Health. 2012;59:286-93.

53. Faires MC, Tater KC, Weese JS. An investigation of methicillinresistant Staphylococcus aureus colonization in people and pets in the same household with an infected person infected pet. J Am Vet Med Assoc. 2009;235:540-3.

54. Aiello AE, Lowy FD, Wright LN, et al. Methicillin-resistant Staphylococcus aureus among US prisoner and military personnel: review and recommendations for future studies. Lancet Infect Dis. 2006;6:335-41.

55. Kazakova SV, Hageman JC, Matava, et al. A clone of methicillin-resistant Staphylococcus aureus among professional football players. N Engl J Med. 2005;352:468-75.

56. Adcock PM, Pasto P, Medley F, et al. Methicillin-resistant Staphylococcus aureus in two child care centers. J Infect Dis. 1998;178:577-80.

57. Kluytmans JA, Nouton JW, Ijzerman Ep, et al. Nasal carriage of Staphylococcus aureus as a major risk for wound infections after cardiac surgery. J Infect Dis. 1995;171:216-9.

58. Tuazon CU, Perez A, Kishaba T, et al. Staphylococcus aureus among insulin-injecting diabetic patients. An increased carrier rate. JAMA. 1975;231:1272.

59. Dinauer MC. Chronic granulomatous disease and other disorders of phagocyte function. Hematol Am Soc Hematol Educ Program. 2005;2005:89-95. 
60. Shadyab AH, Crum-Cianflone NF. Methicillin-resistant Staphylococcus aureus (MRSA) infections among HIV-infected persons in the era of highly active antiretroviral therapy: a review of the literature. HIV Med. 2012;13:319-32.

61. Cimolai N. Ocular methicillin-resistant Staphylococcus aureus infections in a newborn intensive care cohort. Am J Ophthalmol. 2006;142:183-4.

62. Basu S, Kumar A, Kapoor K, et al. Neonatal endogenous endophthalmitis: a report of six cases. Pediatrics. 2013;131: 1292-7.

63. Carey AJ, Duchon J, Della-Latta P, et al. The epidemiology of methicillin-susceptible and methicillin-resistant Staphylococcus aureus in a neonatal intensive care unit, 2000-2007. J Perinatol. 2010;30:135-9.

64. Hori Y, Inoue R, Ikuno Y, et al. Severe methicillin-resistant Staphylococcus aureus infection after multilayer amniotic membrane transplantation. Jpn J Ophthalmol. 2009;1:61-2.

65. Chou Ty, Prabhu S. Clinical course and management of postoperative methicillin-resistant Staphylococcus aureus keratitis in immunocompromised patients: two case reports. Clin Ophthalmol. 2011;5:1789-93.

66. Bödemann M, Kohnen T. Corneal ulcer caused by MRSA after UV/riboflavin cross-linking in a patient with bilateral keratoconus. Ophthalmologe. 2012;109:1112-4.

67. Sotozono C, Inagaki K, Fujita A, et al. Methicillin-resistant Staphylococcus aureus and methicillin-sensitive Staphylococcus epidermidis infections in the cornea. Cornea. 2002;21(7 Suppl):S94-101.

68. Oshima Y, Ohji M, Inoue Y, et al. Methicillin-resistant Staphylococcus aureus infections after scleral buckling procedures for retinal detachments associated with atopic dermatitis. Ophthalmology. 1999; 106:142-7.

69. Lee KM, Lee HS, Kim MS. Two cases of corneal ulcer due to methicillin resistant Staphylococcus aureus in high-risk groups. Korean J Ophthalmol. 2012;24:240-4.

70. Tang HH, Yip PP, Woo CF, et al. Methicillin-resistant Staphylococcus aureus endophthalmitis in a continuous ambulatory peritoneal dialysis patient. J Cataract Refract Surg. 2008;10: 1806-8.

71. Park SS, Rabowsky J. Early postoperative endophthalmitis after pars plana Ahmed valve placement with persistent extraocular infection. Ophthalmol Surg Lasers Imaging. 2007;38:404-5.

72. Feiz V, Redline DE. Infectious scleritis after pars plana vitrectomy because of methicillin-resistant Staphylococcus aureus resistant to fourth-generation fluoroquinolones. Cornea. 2007;26:328-40.

73. Lee JE, Oum BS, Choi HY, et al. Methicillin-resistant Staphylococcus aureus sclerokeratitis after pterygium excision. Cornea. 2007;26:744-6.

74. Rich RM, Smiddy WE, Davis JL. Infectious scleritis after retinal surgery. Am J Ophthalmol. 2008;145:695.

75. Cosar CB, Cohen EJ, Rapuano CJ, et al. Clear corneal wound infection after phacomemulsification. Arch Ophthalmol. 2001;119: 1755-9.

76. Muder RR, Brennan C, Goetz AM. Infection with MRSA among hospital employee. Infect Control Hosp Epidemiol. 1993;14: 576-8.

77. Solomon R, Donnenfeld ED, Perry HD, et al. Methicillinresistant Staphylococcus aureus infectious keratitis following refractive surgery. Am J Ophthalmol. 2007;143:629-34.

78. Woodward M, Randelman JB. Bilateral methicillin-resistant Staphylococcus aureus keratitis after photorefractive keratectomy. J Cataract Refract Surg. 2007;33:316-9.

79. Magli A, Forte R, Rombetto L, et al. Bilateral methicillinresistant Staphylococcus aureus keratitis following hyperopic photorefractive surgery. Int Ophthalmol. 2012;32:47-9.
80. Nomi N, Morishige N, Yamada N, et al. Two cases of methicillin-resistant Staphylococcus aureus keratitis after epi-LASIK. Jpn J Ophthalmol. 2008;52:440-3.

81. Rudd JC, Moshirfar M. Methicillin-resistant Staphylococcus aureus keratitis after laser in situ keratomileusis. J Cataract Refract Surg. 2001;27(3):471-3.

82. Rubinfeld RS, Negvesky GJ. Methicillin-resistant Staphylococcus aureus ulcerative keratitis after laser in situ keratomileusis. J Cataract Refract Surg. 2001;9:1523-35.

83. Karth PA, Karth JW. Endophthalmitis following photorefractive keratectomy with a history of radial keratotomy: a case report. J Ophthalmic Inflamm Infect. 2013;11:1186-9.

84. Forster W, Becker K, Hungermann D, et al. Methicillin-resistant Staphylococcus aureus keratitis after excimer laser photorefractive keratectomy. J Cataract Refract Surg. 2002;28:722-4.

85. Tarabishy AM, Hall GS, Procop GW, et al. Bacterial culture isolates from hospitalized pediatric patients with conjunctivitis. Am J Ophthalmol. 2006;142:678-80.

86. Ho V, Ho LY, Ranchood TM, et al. Endogenous methicillinresistant Staphylococcus aureus endophthalmitis. Retina. 2011; 31:596-601.

87. Wang R, Braughton KR, Kretschmer D, et al. Identification of novel cytolytic peptides as key virulence determinants for community associated MRSA. Nat Med. 2007;13:1510-4.

88. Periasamy S, Joo HS, Duong AC, et al. How Staphylococcus aureus biofilms develop their characteristic structure. Proc Natl Acad Sci USA. 2012;109:1281-6.

89. Foster TJ. Immune evasion by staphylococci. Nat Rev Microbiol. 2005;3:948-58.

90. Kotlus BS, Rogers IT, Udell IJ. Dacryocystitis caused by community-onset methicillin resistant Staphylococcus aureus. Ophthal Plast Reconstr Surg. 2005;21:371-5.

91. Rutar T, Chambers HF, Crawford JB, et al. Ophthalmic manifestations of infections caused by the USA 300 clone of community-associated methicillin-resistant Staphylococcus aureus. Ophthalmology. 2006;113:1455-62.

92. David MZ, Glikman D, Crawford SE, et al. What is community associated methicillin-resistant Staphylococcus aureus? J Infect Dis. 2008;197:1235-43.

93. Amato M, Pershing S, Walvick M, et al. Trends in ophthalmic manifestations of methicillin-resistant Staphylococcus aureus (MRSA) in a northern California pediatric population. J AAPOS. 2013;17:243-7.

94. Naimi TS, LeDell KH, Como-Sabetti K, et al. Comparison of community and health care-associated methicillin resistant Staphylococcus aureus infection. JAMA. 2003;290:2976-84.

95. Lichtinger A, Yeung SN, Kim P, et al. Shifting trends in bacterial keratitis in Toronto: an 11 year review. Ophthalmology. 2012;119:1785-90.

96. Deramo VA, Lai JC, Winokur J, et al. Visual outcome and bacterial sensitivity after methicllin-resistant Staphylococcus aureus-associated acute endophthalmitis. Am J Ophthamol. 2008;145:413-7.

97. Major JC, Engelbert M, Flynn HW Jr, et al. Staphylococcus aureus endophthalmitis: antibiotic susceptibilities, methicillin resistance, and clinical outcomes. Am J Opthalmol. 2010;149: 278-83.

98. Mehra P, Caiazzo A, Bestgen S. Odontogenic sinusitis causing orbital cellulitis. J Am Dent Assoc. 1999;130:1086-92.

99. Charalampidou S, Connell P, Fennell J, et al. Preseptal cellulitis caused by community acquired methicillin resistant Staphylococcus aureus (CAMRSA). Br J Ophthalmol. 2007;12:1723-4.

100. Soon VT. Pediatric subperiosteal orbital abscess secondary to acute sinusitis: a 5-year review. Am J Otolaryngol. 2011;32: $62-8$. 
101. Juthani V, Zoumalan CI, Lisman RD, et al. Successful management of methicillin-resistant Staphylococcus aureus orbital cellulitis after blepharoplasty. Plast Reconstr Surg. 2012;126: $305 \mathrm{e}-7 \mathrm{e}$.

102. Mathias MT, Horsley MD, Mawn LA, et al. Atypical presentations of orbital cellulitis caused by methicillin-resistant Staphylococcus aureus. Ophthalmology. 2012;119:1238-43.

103. Peña MT, Preciado D, Orestes M, et al. Orbital complications of acute sinusitis: changes in the post-pneumococcal vaccine era. JAMA Otolarynogl Head Neck Surg. 2013;139:223227.

104. Vaska V, Grimwood K, Gole GA, et al. Community-associated methicillin-resistant Staphylococcus aureus causing orbital cellulitis in Australian children. Pediatr Infect Dis J. 2011;. doi:10. 1097/INF.0b013e318224fda5.

105. Kubal A, Garibaldi DC. Dacryoadenitis caused by methicillinresistant Staphylococcus aureus. Ophthal Plast Reconstr Surg. 2008;24:50-1.

106. Chandravanshi SL, Sutrakar SK, Bajaj N. Community-acquired methicillin-resistant Staphylococcus aureus bilateral acute dacryocystitis in a neonate. Indian J Ophthalmol. 2012;60:155-6.

107. Rutar T. Vertically acquired community methicillin-resistant Staphylococcus aureus dacryocystitis in a neonate. J AAPOS. 2009;13:79-81.

108. Elmann S, Pointdujour R, Blaydon S, et al. Periocular abscesses following brow epilation. Ophthal Plast Reconstr Surg. 2012;28: 434-7.

109. Enright MC, Robinson DA, Randle G, et al. The evolutionary history of methicillin-resistant Staphylococcus aureus (MRSA). Proc Natl Acad Sci USA. 2002;99:7687-92.

110. - Asbell PA, Sahm DF, Shaw D, et al. Increasing prevalence of methicillin resistance in serious ocular infections caused by Staphylococcus aureus in the United States: 2000-2005. J Cataract Refract Surg. 2008;34:814-8. The first large nationwide multi-institution report to confirm the increasing prevalence of MRSA in serious ocular infections.

111. $\bullet$ McDonald M, Blondeau JM. Emerging antibiotic resistance in ocular infections and the role of fluoroquinolones. J Cataract Refract Surg. 2010;36:1588-98. A comprehensive review of the emerging antibiotic resistance in ocular infections specifically among the fluoroquinolone class of antibiotics.

112. Hövding G. Acute bacterial conjunctivitis. Acta Ophthalmol (Oxf). 2008;86:5-17.

113. Mantadakis E, Maraki S, Michailidis L, et al. Antimicrobial susceptibility of Gram-positive cocci isolated from patients with conjunctivitis and keratitis in Crete, Greece. J Microbiol Immunol Infect. 2013;46:41-7.

114. Sahm D, Marsilio MK, Piazza G. Antimicrobial resistance in key bloodstream bacterial isolates: electronic surveillance with the Surveillance Network Database-USA. Clin Infect Dis. 1999;29:259-63.

115. Hoisi S, Kikuchi K, Sasaki T, et al. Postantibiotic effects and bactericidal activities of levofloxacin and gatifloxacin at concentrations simulating those of topical ophthalmic administration against fluoroquinolone-resistant and fluoroquinolonesensitive methicillin-resistant Staphylococcus aureus strains. Antimicrob Agents Chemother. 2008;52:2970-3.

116. Fitzgerald-Hughes D, Devocelle M, Humphrey H. Beyond conventional antibiotics for the future treatment of methicillinresistant Staphylococcus aureus infections: two novel alternatives. FEMS Immunol Med Microbiol. 2012;65:399-412.

117. Liu C, Bayer A, Cosgrowve SE, et al. Clinical practice guidelines by the infectious diseases society of America for the treatment of methicillin-resistant Staphylococcus aureus infections in adults and children. Clin Infect Dis. 2011;52:e18-155.

118. Sotozono C, Fukuda M, Ohish, et al. Vancomycin ophthalmic ointment $1 \%$ for methicillin resistant Staphylococcus aureus or methicillin-resitant Staphylococcus epidermidis infections: a case series. BMJ Open. 2013;3:e001-6.

119. Ikeda E, Inoue T, Asari S, et al. Local treatment of methicillinresistant Staphylococcus aureus conjunctivitis with short-term high concentrated minocycline ointment. Jpn J Ophthalmol. 2011;55:576-8.

120. $\bullet$ Cheung GYC, Otto M. The potential use of toxin antibodies as a strategy for controlling acute Staphylococcus aureus infections. Expert Opin Ther. Targets. 2012;16:601-12. A nice directed review of the toxins involved in $S$. aureus pathogenesis and the possible target points for immune directed therapy.

121. Suzuki T. A new target for Staphylococcus aureus associated with keratitis. Cornea. 2011;30:S34-40.

122. Koyama N, Inokoshi J, Tomoda H. Anti-infectious agents against MRSA. Molecules. 2012;18:204-24.

123. Shanmuganathan VA, et al. External ocular infections due to methicillin-resistant Staphylococcus aureus (MRSA). Eye. 2005;19:284-91.

124. Adebayo A, et al. Shifting trends in in vitro antibiotic susceptibilities for common bacterial conjunctival isolates in the last decade at the New York eye and ear Infirmary. Graefes Arch Clin Exp Ophthalmol. 2011;249:111-9.

125. Gould LA, et al. Acute suppurative bacterial dacryoadenitis: a case series. Br J Ophthalmol. 2013;97:735-8.

126. Ursea R, et al. Bleb associated endophthalmitis with methicillinresistant Staphylococcus aureus. Br J Ophthalmol. 2012;94:390.

127. Shah MK, et al. Increasing prevalence of methicillin resistance in Staph aureus infections, a 26-year laboratory survey (1984-2010). Ocular Microbiology and Immunology Group45th Annual Meeting, Orlando, Florida, 2011, abstract. 